\title{
LA BATALLA DE SANTIAGO. CRÓNICA DE UNA CUARENTENA EN LA CAPITAL DE CHILE
}

\section{THE BATTLE OF SANTIAGO. CHRONICLE OF A QUARANTINE IN THE CAPITAL OF CHILE}

\author{
Pedro Azócar Guzmán*
}

RESUMEN

La pandemia de CoviD-19 golpeó a Chile en medio de una crisis político social caracterizada por una dura confrontación entre la ciudadanía y sus instituciones, además, de una profunda crítica al modelo económico instaurado por la dictadura de Augusto Pinochet cuyo sustento institucional es la Constitución de 1980. El gobierno derechista de Sebastián Piñera intentó sacar réditos políticos de la pandemia del coronavirus, utilizarla para reafirmarse en el poder, pero la emergencia sanitaria evidenció aún más las profundas desigualdades sociales que subsisten en el país a 30 años de la recuperación de la democracia. Chile aparece doblemente golpeado: por un lado, enfrenta una profunda fractura social $y$, por otro lado, sufre la debacle del coronavirus. En este complejo cuadro, los chilenos deberán resolver, mediante un plebiscito, si convocan o no a una convención constituyente para sepultar definitivamente la Constitución de Pinochet. Este artículo es una aproximación a ese escenario.

PALABRAS CLAVE: CHILE * VIRUS * DESIGUALDAD SOCIAL * NEOLIBERALISMO * GRUPO DE INTERÉS * SALUD

\section{ABSTRACT}

The Covid-19 pandemic hit Chile in the middle of a political and social crisis marked by clashes between citizens and institutions, accompanied by a profound critique of the economic model installed by the Augusto Pinochet dictatorship, the institutional foundation of which is the 1980 Constitution. Sebastián Piñera's rightwing administration tried to reap political gain from the pandemic, using it to reassert itself in power, but the health emergency revealed even more starkly the profound social inequalities that persist in the country 30 years after the return to democracy. Thus, Chile has suffered a double blow: on one hand, it faces a profound social fracture, and on the other, the coronavirus 
disaster. It is in this complex scenario that Chileans must vote in a plebiscite to decide whether or not to convene a constitutional convention to bury Pinochet's Constitution for good. This article is an approach to that scenario.

KEYWORDS: CHILE $*$ VYRUS $*$ SOCIAL INEQUALITY $*$ LIBERALISM $*$ INTEREST GROUPS * HEALTH

La ciudad es una bomba de tiempo y tarde o temprano estallará. Una persona sana con Covid-19 tiene más opciones de salvar su vida que otra con una enfermedad crónica. Lo mismo ocurre con los países. Aquellos con sistemas políticos afectados por patologías no resueltas tienen poca probabilidad de sobrevivir al virus. Es el caso de Chile.

"Otro fin de mundo es posible", se lee en algunos muros de la comuna de Nuñoa, un barrio de clase media ubicado al sur oriente del centro de Santiago en la Región Metropolitana, la capital del país sudamericano, que concentra una población que bordea los ocho millones de habitantes en un territorio con poco más de 17.

La ciudad de Santiago es el epicentro de lo que el gobierno chileno denominó "la guerra contra el coronavirus", un lenguaje bélico replicado en muchos países, pero que en Chile es una muletilla molesta.

Hace solo unos meses, el presidente Sebastián Piñera Echeñique, uso esta misma terminología para aludir a quienes protestaban contra su gobierno y modelo económico, durante el estallido social que se desencadenó a lo largo de todo el país en octubre de 2019.

"Estamos en guerra contra un enemigo poderoso, implacable", dijo el jefe de estado en ese entonces.

Ahora, replicó la frase en este nuevo escenario, calificando de "invisible" al nuevo adversario que, en solo unos días, nuevamente puso en evidencia las injusticias sociales que corroen la sociedad chilena.

Si desde Estados Unidos, Donald Trump logró lo que no pudo hacer la Unión Soviética durante toda la guerra fría al desprestigiar ante el mundo el "american way of life" de forma grotesca, el gobierno de Piñera consiguió destruir en pocos meses, el mito del éxito capitalista del Chile post Pinochet, de la supuesta eficiencia del neoliberalismo desregulado que instauraron los "Chicago Boys" en el país durante la dictadura, en lo que alguna vez el mundo calificó como "el milagro económico chileno".

El lunes 19 de mayo, vecinos de varias comunas de la zona sur de la ciudad rompieron las reglas de la cuarentena decretada de manera más amplia en la capital recién el viernes 15 de ese mes. Levantaron barricadas, cortaron calles y salieron a tocar las cacerolas para exigir ayuda: "tenemos hambre", era la consigna de quienes golpeaban ollas vacías de alimento.

Esta acción de protesta que se conoce acá como "caceroleo", surge durante el gobierno del presidente, Salvador Allende (19701973). Mujeres de la ultraderecha acomodada, se manifestaban de esta forma en las calles para protestar contra el desabastecimiento de productos, promovido por la misma derecha para desestabilizar el proyecto socialista de Allende y allanar el camino a lo que sería el golpe de estado de 1973, que derivó en una dictadura que se prolongó por largos 17 años.

Fue bajo este régimen autoritario que se implementó en Chile el modelo de libre mercado $y$ un marco institucional para garantizarlo a perpetuidad, la tristemente célebre Constitución de Pinochet.

La escritora y periodista, Naomi Klein, lo explica en pocas palabras: "La «doctrina del shock» es la estrategia política de utilizar las crisis a gran escala para impulsar políticas que sistemáticamente profundizan la desigualdad, enriquecen a las elites y debilitan a todos los demás".

Y es así, las crisis permiten implementar políticas que se justifican como necesarias en esos contextos, pero en el tiempo se eternizan $y$ son instrumentalizadas por el poder para consolidar privilegios que necesariamente 
culminan perjudicando a las personas. En Chile lo sabemos bien.

Así ocurrió bajo el régimen de Pinochet $y$ los perjudicados reeditaron los "caceroleos" en las calles. Esta vez eran ciudadanos sumidos en la miseria y el hambre, resultado de las transformaciones económicas de la dictadura aplicadas en Chile por los discípulos de Milton Friedman, egresados de la escuela de Chicago $y$ que derivaron en una debacle social en el contexto de la crisis de la economía global que ocurrió a inicios de los 80 .

Hoy día sigue el mismo modelo amparado por la misma institucionalidad y enfrentamos una nueva contracción económica que se arrastra desde antes de la pandemia. La enfermedad no hizo más que agudizarla.

Las medidas restrictivas aplicadas por el gobierno para frenar la propagación del Covid19, si bien, fueron escasas durante los primeros dos meses del brote, afectaron como siempre a los más pobres, a quienes tienen menos defensas para enfrentar lo que Piñera llamó la "pandemia social".

A diferencia de otros países, el gobierno de Chile no implementó cuarentenas totales para evitar la propagación del SARS-CoV2, sino que lo hizo de forma focalizada para resguardar el funcionamiento del mercado de consumo, motor del capitalismo local. Con total pragmatismo, los tecnócratas instalados en el poder ejecutivo asumieron que una cuarentena total implicaba dejar sin sustento a vastos segmentos de la población que operan en la economía informal, los mismos que ahora protestan por comida.

El empleo en este ámbito, según cifras del Instituto Nacional de Estadísticas (INE), equivale casi al $30 \%$ de la fuerza de trabajo del país. Solo en la capital cerca de un millón de personas sobrevive de esta forma a lo que se suma, según datos de diciembre de 2019, que hay casi 300 mil trabajadores desempleados, números que cambiaron drásticamente al alza con la propagación de la pandemia. Hoy la cesantía en la ciudad de Santiago supera el 15\% y según un estudio de la Universidad de Chile, la cifra a nivel país sobrepasaría el $20 \%$, si sumamos a quienes no están saliendo a buscar empleo a causa de la pandemia. Hoy se estima que dos millones y medio de personas están sin trabajo en todo el país.

La imagen de éxito económico que proyecta Chile hacia el exterior difiere drásticamente con la realidad local. Según la encuesta de Caracterización Socioeconómica Nacional (CASEN 2017-2018), la pobreza multidimensional antes de la pandemia alcanzaba al 20,7\% de la población, poco más de 3 millones 500 mil personas que enfrentaban carencias en salud, educación, vivienda, trabajo y seguridad social, entre otras.

Pero las cifras eran peores aún. La Fundación Sol, un centro independiente de investigación socioeconómica, determinó que el $29,4 \%$ de los chilenos vivían realmente en la pobreza, es decir, 5 millones 200 mil personas.

Lo que sucede es que el gobierno, al realizar el cálculo, suma como ingresos de la gente lo que en verdad son derechos socioeconómicos adquiridos, como algunos subsidios que entrega el Estado e, incluso, agrega los eventuales activos de una persona bajo el concepto "alquiler imputado":

...la metodología oficial establece que una familia que es dueña de una vivienda (...), se le imputa como ingreso del hogar el equivalente al costo que tiene un arriendo en el sector o manzana donde habita. Así por ejemplo en el caso de una persona sin trabajo, que tiene 65 años y que es dueño de su vivienda o sigue pagándola vía dividendos, tendrá un ingreso equivalente a lo que se paga en arriendo en el lugar donde vive. Esta persona puede que actualmente no tenga dinero siquiera para comer, pero en las encuestas aparecerá con un ingreso por alquiler imputado y si ese dinero es mayor al monto establecido para la línea de pobreza correspondiente para la composición del hogar, se clasificará como una persona no pobre (Durán y Kremerman, julio de 2017, p. 4).

Lo más grave, afirma la investigadora de este organismo, Valentina Doniez, "es que los salarios que ganan los chilenos como fruto 
de su trabajo son insuficientes para que ellos puedan salir de esta condición de pobreza”. El $70 \%$ de los chilenos percibe un salario mensual que no supera los 500 mil pesos, equivalentes a unos 770 dólares.

Lo que sucede en verdad, es que el manejo estadístico de todos los gobiernos de la postdictadura apunta a bajar los indicadores sociales para dar una buena imagen internacional del sistema económico. Buscan mantener vivo el mito del exitoso modelo neoliberal chileno, más que dar cuenta de la situación real de las personas que viven en la pobreza. La gente no importa demasiado cuando prima la lógica de los números.

En Chile, el "Intendente" es la autoridad del poder ejecutivo que gobierna en las regiones, no es de elección popular sino designado por el presidente de turno. En el caso de la Región Metropolitana, capital del país, el cargo lo detenta Felipe Guevara, quién ante las demandas y protestas de la gente por comida expreso: "el coronavirus debe estar muy feliz por la forma en que actúan estas personas".

Minutos más tarde, varios centenares de efectivos de Carabineros de Fuerzas Especiales - la desprestigiada policía nacional- reprimieron las protestas con carros lanza aguas, bombas lacrimógenas y detuvieron a una treintena de vecinos. Por la noche, las barricadas se replicaron en otras comunas de la ciudad y los días siguientes se extendieron aún más, incluso, a otras regiones del país.

La mecha del descontento que estalló en octubre de 2019, contenida en marzo por el coronavirus, empezó nuevamente a arder. La ciudad de Santiago es una bomba de tiempo que tarde o temprano volverá a estallar.

Por eso pienso en ese graffiti que se reitera en varios muros de la comuna de Nuñoa: "Otro fin de mundo es posible". La ironía es certera porque la debacle política, la pandemia del Covid-19, la recesión económica inminente, el desempleo y el hambre no son nada, en comparación con la capacidad que tenemos los humanos para empeorar aún más las cosas en medio de una crisis, donde, la calaña de algunos de los líderes que nos gobiernan es el verdadero problema. Da miedo que vean en la pandemia una oportunidad.

Por eso lo escrito en el muro nos interpela, ya que somos solo nosotros quienes podemos generar nuevas opciones para arruinarlo todo. Otro fin de mundo es posible porque si hay algo que sobra, es creatividad para lograr ese otro final. No se trata de cambiar el desenlace, sino de cómo construir esa destrucción. Es la lógica de la guerra que imponen nuestros gobernantes, una guerra donde los chilenos perdimos la certeza de quién realmente es el enemigo, si el coronavirus, o quienes dirigen la batalla contra él.

Lo cierto es que muchos caerán en este combate: "enfrentamos un enemigo invisible y poderoso", dirán sus epitafios.

\section{LOS GENERALES}

Los síntomas del malestar social que evidenciaron el descontento con el sistema económico y político vigentes los vimos aflorar con fuerza en octubre de 2019. Las protestas ciudadanas hicieron tambalear al gobierno del presidente Sebastián Piñera, empresario líder de una alianza derechista que ganó el poder por segunda vez en 2017, en unas elecciones donde la abstención superó el 50\% del padrón electoral. Piñera asume el mando con solo el $26,4 \%$ de los votos.

El primer caso de Covid-19 en Chile fue informado el 3 de marzo de 2020 por el Ministro de Salud, Jaime Mañalich, médico nefrólogo expulsado en 2015 del colegio de la orden por faltas a la ética y muy desprestigiado por falsear información estadística para alterar las llamadas "listas de espera", que consignan la nómina de los enfermos que aguardan su turno para ser tratados en el sistema público de salud chileno, según Mañalich: "uno de los más eficientes del planeta".

Una afirmación que irrita y contradice las cifras despiadadas que entrega el propio gobierno en torno a las listas de los que esperan por salud. El primer semestre de 2018, murieron 9724 personas aguardando atención médica en el sistema público de salud chileno, un aumento del $54 \%$ respecto al año precedente. Consultadas las autoridades sobre el punto, 
argumentaron en ese entonces, que el alza se originó en mejoras de los sistemas estadísticos de los servicios de salud. Es decir, aprendieron a contar bien a los muertos. Respuestas de este tipo fueron las que impulsaron el descontento de octubre.

Fue este contexto de crisis, lo que hizo que muchos en la derecha vieran la llegada del coronavirus como una oportunidad para neutralizar al movimiento social que entró en receso durante los meses de verano, pero que en marzo prometía volver a las calles para preparar el escenario del plebiscito programado para el 26 de abril (hoy aplazado para octubre), donde se votaba la opción de formular una nueva constitución que eliminara definitivamente la de Pinochet, que aún regula la política del país.

La derecha más absolutista y fanática llegó a decir que "el coronavirus fue lo mejor que pudo pasarle políticamente a Chile (...). El tema constitucional (...), pasó a un segundo plano". Las palabras son de Axel Kaiser, abogado y columnista del Diario Financiero - un periódico exclusivo de los empresarios - que opera como una suerte de ideólogo ultraderechista y es director de la "Fundación para el Progreso", un centro de estudios financiado por el controvertido multimillonario, Nicolás Ibáñez Scott, del que también es parte el ex Ministro de Cultura de Piñera, Mauricio Rojas Mullor. Me detengo en este último, porque debió renunciar al cargo en el gabinete debido a que relativizó los crímenes de la dictadura y criticó duramente al Museo de la Memoria, que recuerda las atrocidades del régimen de Pinochet: "ese es un museo de la izquierda, para contar una versión falsa de la historia de Chile", dijo en su oportunidad el ahora exministro. Lo cuento, para graficar la calaña de los personajes que son o han sido parte de este gobierno. Por eso no es extraño, que el ejecutivo también viera una oportunidad en el virus y buscara sacar beneficio de ella.

Sebastián Piñera, inició el año 2020 con la peor aprobación lograda por un presidente de Chile desde el retorno a la democracia. A inicios de año, la prestigiosa encuestadora del Centro de Estudios Públicos (CEP), determinó que solo un $6 \%$ de los chilenos aprobaba su gestión mientras que el $82 \%$ rechazaba su mandato. En ese contexto, poco tenía el gobierno que perder $y$ mucho que ganar si jugaba bien sus cartas. Marzo prometía ser el mes de la reactivación de la protesta social y ese mismo mes el virus llegaba a Chile, un escenario que podría ser propicio para recuperar el apoyo perdido.

Durante su primer mandato presidencial (2010-2014), Piñera logró una gran aprobación ciudadana luego del exitoso rescate de $33 \mathrm{mi}-$ neros que quedaron atrapados en un túnel 720 metros bajo tierra, en la mina San José, al norte del país. Como buen especulador bursátil, Piñera es un apostador que no teme correr riesgos y en ese momento lo hizo bien. Aunque era poco probable, apostó primero a que los mineros estaban con vida y acertó; luego, jugó a rescatarlos ilesos lo que se logró tras 69 días de trabajo, con una puesta en escena televisada en vivo para todo el mundo y un costo superior a los 20 millones de dólares.

Fue su gran éxito como gobernante y la experiencia marcó a fuego su primera gestión, por lo que muchos vieron en la pandemia, la posibilidad de replicar la jugada. La lógica empresarial de quienes nos gobiernan se expresa siempre en la muletilla: "las crisis son oportunidades" y en esa lógica el coronavirus podía ser aprovechado porque planteaba un nuevo escenario al desviar la atención del conflicto político. Por eso fue bienvenido en la derecha porque era lo que esperaba el gobierno para demostrar su capacidad de gestión, algo de que hacen gala los empresarios chilenos y por sobre todo Piñera, que exhibe su gran fortuna como prueba tangible de aquello.

En este escenario de "guerra contra el enemigo invisible", Piñera asume el generalato estratégico y su Ministro de Salud, Jaime Mañalich, el mando táctico de las tropas.

El primero busca utilizar la pandemia como una oportunidad para salvar su gobierno $y$ alejar el fantasma de las protestas que lo hicieron tambalear en octubre de 2019; el segundo, para proyectar su carrera política, quizás, hasta una eventual candidatura a la presidencia. 


\section{LA BATALLA}

Las primeras escaramuzas contra el virus se registraron a inicios de marzo. La pandemia llegó desde el extranjero, la trajeron aquellos chilenos que regresaban de sus vacaciones veraniegas desde Asia o Europa, los primeros brotes de importancia ocurrieron por ello en el barrio alto de Santiago, no todos pueden darse el lujo de cruzar el océano.

Para quienes no conocen la capital de Chile hay que explicar que, como todo el país, Santiago es una ciudad muy segregada donde el poder político y económico se concentra en la zona nororiente, en las comunas más ricas en términos de ingresos que son, Vitacura, Las Condes, Lo Barnechea, todas muy alejadas del centro, ubicadas en los faldeos de la imponente Cordillera de los Andes, lo que vale el nombre de "barrio alto" a toda esa zona de la ciudad.

Estas comunas cuentan con excelente infraestructura, accesos expeditos y comercios exclusivos. "Parece otro país", es el comentario habitual de los menos afortunados que solo van de visita a ese sector de la ciudad, donde son observados como "bichos raros" o sospechosos, por los sistemas de vigilancia privada que contratan los municipios más ricos de Chile.

El río Mapocho, es el único cauce fluvial que atraviesa Santiago, su cada vez más escaso torrente es testigo de cómo se distribuye la desigualdad social en la capital de Chile.

Desciende desde la cordillera hacia el poniente dividiendo la ciudad en dos. Si seguimos su curso desde los faldeos montañosos iremos bajando desde Lo Barnechea y Las Condes (el barrio alto), hacia Providencia, otra comuna con alto poder adquisitivo que culmina en Plaza Italia, hoy renombrada como "Plaza Dignidad", luego que, durante las protestas de octubre, fuera el epicentro de la movilización social contra el gobierno y punto de encuentro diario de millones de chilenos que pedían a gritos un cambio en el sistema.

Pasado este punto neurálgico, que es como la frontera social que divide a los ricos de los pobres, el río cruza la zona centro, la comuna de Santiago propiamente tal, el barrio cívico donde funciona el aparato del Estado y se levanta el Palacio de la Moneda, la casa de gobierno donde murió el presidente Salvador Allende y que debió ser reconstruida luego de ser bombardeada por Pinochet en septiembre 1973.

Al norte del río se extienden, entre otras, las comunas de Recoleta, Independencia, Conchalí y Renca, importantes centros de comercio que albergan mucha población migrante. Al sur, la ciudad avanza varios kilómetros a lo largo de las populosas comunas de Pedro Aguirre Cerda, San Miguel, Lo Espejo, el Bosque, la Pintana, La Florida, Puente Alto, Maipú y San Bernardo.

A medida que el río se aleja de la cordillera hacia el poniente y la ciudad del río hacia el sur 0 al norte, aumenta la pobreza en los barrios y comunas. Así, cuando el Mapocho cruza Cerro Navia o Pudahuel hacia la costa, el paisaje cambia drásticamente $y$ vemos "viviendas sociales" y poblaciones levantadas a pulso por los vecinos que son resultado de "tomas de terreno", ocupaciones ilegales de tierra realizadas por gente sin casa. La "toma" es única forma en que muchos chilenos logran concretar el sueño de una vivienda propia.

Durante la dictadura, la segregación social de la ciudad se agudizó drásticamente. El régimen desalojó aquellas tomas de terreno que ocupaban sitios con proyecciones para el negocio inmobiliario que extendió horizontalmente la capital sin más planificación que la ley de la oferta y la demanda. Estas personas fueron reubicadas en la zona poniente, sur y norte de la ciudad, lo más lejos posible del centro y de los barrios acomodados.

Construyeron bloques de apartamentos $y$ poblaciones con miles de pequeñas casas que se convirtieron en verdaderos guetos de pobreza donde los vecinos viven hacinados, sin acceso a servicios básicos, ni espacios públicos, como parques o plazas. Es en estas áreas de la Región Metropolitana donde residen los trabajadores y trabajadoras que laboran para los que viven en las zonas más ricas de la capital. Ahí también se instalan los inmigrantes y quienes ejercen el trabajo informal en las calles y comercios. Son los "barrios bajos" donde duerme la gente que mueve la economía del país.

Este es el escenario bélico que enfrenta la amenaza del nuevo coronavirus. Bolsones 
de pobreza y segregación social, marginalidad territorial que obliga a que millones de capitalinos se desplacen cada día por la ciudad en un sistema de transporte público abarrotado, campo fértil para la propagación de la epidemia. Todos obligados a recorrer kilómetros para llegar a sus lugares de trabajo o estudio, ubicados lejos de las zonas periféricas.

Los estrategas a cargo de esta "batalla", declinaron permitir la participación real de otros actores sociales en la respuesta a la pandemia. El Ministro de Salud, Jaime Mañalich y el presidente, Sebastián Piñera, se convirtieron en los principales gestores de la estrategia de Chile contra el coronavirus. Se rodearon de un reducido "panel de expertos" y a puertas cerradas definieron su estrategia en la Moneda, dejando fuera al Colegio Médico, a la Sociedad Chilena de Epidemiología, al Colegio de Enfermeras $y$ en general, a todos los gremios de la salud, eso al menos, en un comienzo.

Ambos personeros repitieron hasta el cansancio en los medios de comunicación que se habían "preparado desde enero", que estaba "todo bajo control", que los servicios de salud resistirían. Mañalich llegó a decir que el sistema sanitario tenía la capacidad "para enfrentar sin problema un brote de hasta 430 mil contagios" y Piñera, que Chile estaba mejor preparado que España o Italia para enfrentar esta "guerra contra el enemigo invisible".

Ambos se resistieron a suspender el inicio de clases en colegios y universidades programado para marzo, pero ante las presiones de alcaldes, profesores, rectores universitarios, estudiantes, padres $y$ apoderados, terminaron por ceder $y$ anunciaron que retrasarían el inicio del año escolar.

Luego, ambos también, se resistieron a cerrar los grandes centros comerciales que hay en la ciudad, puntos de aglomeración de miles de personas que también movilizan miles de millones de pesos cada día. Los trabajadores protestaron y los alcaldes tomaron la iniciativa $y$ amenazaron con emitir decretos de cierre, finalmente los Malls cerraron sus puertas gracias a estas presiones.

Para el ingreso de chilenos y extranjeros de otros países no hubo mayor control en los aeropuertos y fronteras, solo una toma de temperatura al llegar y la obligación de llenar un formulario con el compromiso de guardar cuarentena por 14 días. Muchos viajeros lo completaron con datos falsos, lo que hizo que después fuera imposible ubicarlos $y$, por ende, saber si cumplían o no con el aislamiento. En verdad no hubo fiscalización alguna a quienes llegaron del extranjero.

Pero el 18 de marzo, con 238 casos positivos de Covid-19 en el país, el gobierno se apresuró en decretar estado de catástrofe y cuatro días más tarde instauró el toque de queda y sacó militares armados a las calles para hacerlo cumplir. Piñera replicó lo que hizo durante el estallido social de octubre de 2019, cuando con el ejército resolvió combatir a ese otro "enemigo poderoso" que reclamaba por mejores condiciones de vida y exigía erradicar definitivamente la Constitución de Pinochet de la faz de la tierra.

Dos días más tarde, el viernes 20, medio centenar de alcaldes de diferentes comunas del país, incluso algunos militantes oficialistas, solicitaron al gobierno decretar una cuarentena total para evitar la propagación del virus. El ministro Mañalich respondió que pedir eso era absurdo y los acusó de utilizar la pandemia con fines electorales: "Lo que están pidiendo los alcaldes, algunos con afanes populistas, otros con afanes electorales, sin ninguna duda, es una insensatez completa", dijo y argumentó que en España la cuarentena había fracasado. Ese día ya había 434 casos confirmados de Covil-19 en Chile.

El 25 de marzo se contabilizaron 1252 contagios y el gobierno anunció la cuarentena para siete comunas de la capital, casi todas del "barrio alto". Lo Barnechea, Vitacura, las Condes, Providencia, Ñuñoa e Independencia, inauguraron lo que el Ministro de Salud llamó, "cuarentenas progresivas". Su argumento: que esas zonas concentraban los mayores brotes de la enfermedad por lo que era necesario aplicar estrictas restricciones, pero hubo algo muy curioso en estas medidas.

Los habitantes de las comunas pobres obligados a trabajar en el barrio alto no tuvieron restricción alguna para ingresar a la zona 
en cuarentena y seguir realizando sus labores. Así fue como el virus se propagó poco a poco por toda la ciudad y el enemigo demostró no solo que era invisible sino también, silencioso.

La estrategia implementada consistió en ralentizar la propagación de la enfermedad sin frenar la actividad económica: "El esfuerzo no es que nadie se contagie, sino que la mayor cantidad de gente se contagie de una manera lenta para que no ocurra un momento en que hay tantas personas enfermas que el sistema sanitario no pueda sacarla adelante", explicó a inicios de abril el Ministro de Salud para justificar sus medidas. El día 2 de ese mes, ya había 3737 contagios de Covid-19 en Chile.

Fue ahí, cuando el presidente Piñera realizó un gesto inexplicable para muchos. De regreso a su casa desde la Moneda, detuvo a la comitiva presidencial en Plaza Italia (renombrada Dignidad por la ciudadanía) y se fotografío a solas al pie del monumento al General Baquedano, punto neurálgico de las protestas de octubre en su contra, ubicado en Providencia, comuna en cuarentena. La acción del presidente fue vista como una provocación y planteó muchas preguntas. ¿Dónde está el énfasis de su gestión realmente? ¿En la gravedad de la pandemia que amenaza al país o en la particular amenaza que implicó para su gobierno el estallido social de octubre? Nunca hubo una respuesta.

\section{MAPAS DE GUERRA}

"No puedes combatir el fuego con los ojos vendados y no podemos detener esta pandemia si no sabemos a quién está infectando". El director de la Organización Mundial de la Salud (oms), Tedros Adhanom Ghebreyesus, insistió hasta el cansancio en la necesidad de hacer las pruebas diagnósticas necesarias para visualizar el curso de la pandemia: "Prueba todos los casos sospechosos. El aislamiento y el rastreo de contactos es la columna vertebral de la respuesta y para hacer eso probar y aislar", reiteró hasta ser majadero.

Es obvio que todo estratega sabe que tener un buen mapa del territorio enemigo es clave para librar una batalla y en el caso del coronavirus este mapa son los datos.
Las primeras alertas respecto al manejo de la información epidemiológica por parte del Gobierno de Piñera vinieron del mundo científico. Los informes diarios entregados por el ministro y sus asesores evidenciaban anomalías, al ser contrastados con la manera en que evolucionaba la pandemia en casi todos los países del mundo.

El reporte de los nuevos contagios se mantuvo extrañamente aplanado durante demasiados días en los meses de marzo y sobre todo en abril, bordeando casi siempre los 300 casos nuevos cada día. No había progresión matemática ni geométrica, una suerte de "meseta", dijo el ministro Jaime Mañalich y el presidente Sebastián Piñera completó la frase planteando que ya debíamos prepararnos para volver a una "nueva normalidad".

El Colegio Médico, prestigiados científicos y epidemiólogos, universidades y centros de estudio independientes, criticaron abiertamente la forma en que el gobierno manejaba los datos. Pese a tener la capacidad de realizar 12 mil testeos diarios, no se hacían ni la mitad. Todo indicaba que la cifra de casos se mantenía artificialmente plana manejando los testeos. También era abultada la cifra de recuperados.

Poco aportaron también las intervenciones del gobierno $y$, en particular, la arrogancia del Ministro de Salud, Jaime Mañalich. Su evidente falta de empatía y claridad al momento de explicar la situación. El personero llegó a contabilizar a los muertos como recuperados, anunció la creación de un salvoconducto de inmunidad para los sobrevivientes (el carné covid), planteó la posibilidad de que el virus mutara y "se volviera una buena persona" y trató de explicar el alza en la cantidad de contagios como un "aumento no creciente".

En este escenario confuso y pese a todas las advertencias, Piñera insistió en la "nueva normalidad" $y$ a mediados de abril el gobierno ofició instructivos, ordenando el retorno de los trabajadores públicos a sus funciones. Comenzaron a planificar el inicio de las clases en los colegios $y$ universidades, $y$ la reapertura de los grandes centros comerciales de la ciudad.

La Subsecretaria de Salud, Paula Daza, segunda en el gabinete, aseguró que ya estaban 
dadas las condiciones para que la gente saliera a "tomarse un cafecito" y el ministro agregó que bien podía ser "una cerveza o unas empanadas" y reafirmó con ironía que él "siempre consideró que fue un error suspender las clases en los colegios".

Pero el clímax de la "nueva normalidad" vino a fin de mes, cuando el alcalde de la comuna de Las Condes, el militante de la UDI $y$ cercano a Pinochet, Joaquín Lavín, devenido hoy en el candidato presidencial no confeso de la derecha, anunció la reapertura de un emblemático Mall de su comuna, cuya cuarentena se levantó a mediados de abril. El jueves 30, el centro comercial Apumanque abrió sus puertas al público, miles de personas fueron recibidas con aplausos por el propio alcalde al ingreso del recinto. A esa misma hora el Ministerio de Salud informaba 888 nuevos contagios en el país.

Las dudas respecto a los datos del gobierno se profundizaron aún más, cuando se evidenció que la cifra de muertes registrada en el primer trimestre de 2019 era un $12 \%$ más baja que la de 2020 en el mismo periodo. Por redes sociales, muchas personas denunciaron que decesos por Covid-19 de familiares, eran registrados en sus certificados de defunción con otras causas de muerte. El gobierno salió a desmentir estas afirmaciones y reiteró que la tasa de mortalidad de Chile es una de "las más bajas del mundo", la sitúan en poco más del $1 \%$, algo que aun hoy todos discuten, más aun, cuando siempre han tenido problemas para contar a los muertos.

Pero todos estos debates sobre cifras $y$ datos mal computados o derechamente, manipulados, perdieron relevancia cuando la verdad se comenzó a imponer trágicamente los primeros días de mayo, momento en que el discurso del gobierno viró como un vuelo sin escalas de la "nueva normalidad" a la "batalla de Santiago".

Los casos de nuevos contagios registraron un salto cuántico el miércoles 13 cuando el número de Covid-19 positivos aumentó de 1658 a 2502 en un solo día. De ahí en adelante la realidad estalló.
En esa fecha, a 71 días del primer caso detectado en Chile, el gobierno de Sebastián Piñera resolvió decretar cuarentena en 38 comunas de la Región Metropolitana que concentra más del $80 \%$ de los casos confirmados de coronavirus en Chile. Solo en Santiago había más de 66 mil contagios.

A partir de ese minuto, el discurso del gobierno giró del exitismo y la arrogancia precedentes a delimitar las responsabilidades de su fracaso estratégico.

El Ministro de Salud, Jaime Mañalich, culpó a la "irresponsabilidad de la gente" del explosivo brote porque "no respetan el aislamiento y la distancia social" y llegó a decir que decretar antes de tiempo una cuarentena le restaba efectividad a la medida. También culpó a la "desconfianza ciudadana" con las instituciones derivada del estallido social de octubre y negó que haya incidido en algo la idea de "nueva normalidad" instalada por ellos días antes.

\section{CASTILLOS DE NAIPES}

El primer caso de Covid-19 en el mundo lo documentó China en diciembre de 2019. El primer caso en España se informó el 31 de enero de 2020 y en Chile el 3 de marzo, 32 días después.

Todos los científicos que observaron la pandemia desde el comienzo afirmaron que América Latina y Chile corrían con ventaja ya que podían visualizar con anticipación la evolución de la enfermedad en Asia y Europa, aprender de sus experiencias, lo que permitía definir mejor las políticas preventivas, de contención y tratamiento.

Era prácticamente tener la posibilidad de viajar en el tiempo hacia el futuro y definir en base a ello un destino más eficiente, pero nada de eso ocurrió.

"Todos los ejercicios epidemiológicos, las fórmulas de proyección con las que yo me seduje en enero, se han derrumbado como castillo de naipes". Con estas palabras el Ministro de Salud, Jaime Mañalich, esbozó una suerte de autocrítica el 26 de mayo, cuando los contagios en Chile bordeaban los 78 mil casos y ya había 806 muertos. 
Sus palabras ratificaron que no es bueno construir castillos de naipes para enfrentar crisis sanitarias globales, evidenciaron además que la soberbia no sirve para ganar una guerra sino más bien para garantizar la derrota $y$, por sobre todo, pusieron en la palestra el fracaso de la estrategia del Gobierno.

Piñera y Mañalich edificaron su plan sin escuchar a nadie, era su juego, sus cartas, su apuesta. Todos advirtieron lo que venía y no quisieron verlo. Bastaba con observar lo que ocurría en otros países, pero no, ellos querían ganar solos el juego, atesorar para sus proyectos políticos y personales lo que consideraban sería su máxima victoria contra ese "enemigo invisible y silencioso", pero se equivocaron.

Ahora la realidad les muestra que perdieron y por su puesto la culpa no es de ellos, sino de todos los otros, pero los muertos son inocentes. ¿Quién pagará por todas las víctimas caídas en su "batalla de Santiago"? Algo que nadie responde.

A mediados de junio, pocos días después de estas declaraciones, se hizo efectiva la renuncia al gabinete del Ministro de Salud, Jaime Mañalich. Era el fusible que había que sacrificar para salvar al presidente, pero el Ministro antes de partir le lanzó un dardo envenenado. Quien ha "liderado esto desde el primer momento" dijo, es Sebastián Piñera.

El último escándalo que desencadenó su salida se originó en la descarada manipulación de cifras orquestada desde el Ministerio. Mientras la cartera de salud informaba al país que el sábado 13 de junio se contabilizaban 3 mil 101 muertos por Covid-19, el departamento de estadística del mismo gabinete reportaba más de 5 mil decesos a la oms. Ya era demasiado.

Luego de la salida de Mañalich asumió en su reemplazo, Enrique Paris, ex presidente del Colegio Médico que fue parte del comando presidencial de Piñera y que no tiene parentesco alguno con el otro doctor Enrique Paris, asesor del presidente Allende, detenido en el palacio de la Moneda en 1973, asesinado y hecho desaparecer a los pocos días del golpe de estado. Es solo un alcance de nombres.
La llegada de este nuevo ministro obligó a transparentar las cifras reales y conocer el impacto de la pandemia en Chile. Permitió además que el gobierno recogiera algunas propuestas de los especialistas, gremios de la salud, universidades y centros de estudio independientes que no habían sido escuchados. Hubo un cambio en la estrategia para contener la propagación de la enfermedad mediante la búsqueda activa de aquellas personas que habían tenido contacto con alguien contagiado y se multiplicó por tres la aplicación de testeos a la población. El cuadro que todo esto expuso fue dramático.

Antes de terminar agosto Chile contabilizaba más de 400 mil contagiados por Covid-19 $y$ la cifra de muertos a causa de la enfermedad superaba ya las 15 mil personas, se ubicaba así, en el décimo puesto a nivel mundial entre los países que registran la mayor cantidad de casos confirmados, según lo que publica la Universidad Johns Hopkins de Estados Unidos.

\section{"SÓLO EL PUEBLO AYUDA AL PUEBLO"}

A mediados de julio los cacerolazos nuevamente se escucharon en varios puntos del país y en casi todas las comunas de la capital. El gobierno adoptó una serie de iniciativas para apoyar a las personas afectadas por la crisis económica derivada de la pandemia, pero estas no fueron suficientes. El mes anterior, Piñera anunció la entrega de más de dos millones de cajas con alimentos a los sectores más necesitados, pero la imposibilidad de trabajar y la pérdida de ingresos derivada del desempleo acrecentaron el malestar ciudadano. Más de dos millones y medio de personas amenazadas por el hambre, desempleados $y$ trabajadores informales que viven al día ya que si no trabajan no comen, motivaron la reaparición de las "ollas comunes" en los barrios de la ciudad.

Durante la grave crisis económica de 1982 , en plena dictadura, los vecinos de los sectores medios $y$ de menores ingresos se organizaron comunitariamente compartiendo los alimentos que lograban reunir. Un vecino aportaba una taza de arroz, otro un kilo de porotos (frijoles), otro, cebollas recolectadas en la feria 
$y$ así reuniendo entre todos, cocinaban juntos en una gran olla de la que emanaban raciones de comida que se repartían entre la comunidad. Largas filas de hombres, mujeres y niños se formaban fuera de las sedes vecinales, iglesias y casas particulares donde, mujeres generalmente, repartían con grandes cucharones las raciones del almuerzo. Hoy ocurre lo mismo. Son miles las ollas comunes que se han levantado en todo el país bajo el lema "solo el pueblo ayuda al pueblo", respuesta ciudadana al abandono por parte de las autoridades de gobierno.

Pero el caceroleo que partió a mediados de julio y que se replicó casi a fin de ese mes era, por otra razón, los chilenos comenzaron a demandar el retiro de parte de lo ahorrado en sus fondos previsionales para tener liquidez $y$ lograr subsistir en medio de la pandemia.

\section{LA BATALLA DEL $10 \%$}

El sistema previsional chileno conocido como AFP, sigla para designar a las Asociaciones de Fondos de Pensiones, fue implementado en dictadura en 1980, ideado por José Piñera, hermano del actual Presidente de la República.

Piñera es un economista que operó como impulsor de las reformas neoliberales del régimen militar, periodo en el que ocupó los ministerios de Trabajo, Minería y Previsión Social. Al implementar el nuevo sistema previsional, prometió que los trabajadores jubilarían con un monto equivalente al $80 \%$ de su último salario, lo que nunca ocurrió.

El modelo opera en base al ahorro individual que logra un trabajador a lo largo de su vida laboral, donde cada mes, se le retiene el $10 \%$ de su renta bruta, monto que pasa a ser administrado por una AFP, una sociedad anónima privada que reinvierte los recursos que acumula en distintos instrumentos financieros para rentabilizarlos.

El economista chileno, Manuel Riesco, fundador del Centro de Estudios Nacionales Alternativos CENDA, ha estudiado por años este modelo previsional y su opinión es tajante: "El sistema AFP no es un sistema de pensiones sino de ahorro forzoso (...). La mayor parte de dichas cotizaciones, a lo largo de cuatro décadas, han sido desviadas a un fondo que financia inversiones de un pequeño grupo de grandes empresarios, $y$ a pagar comisiones $y$ primas a los gestores del sistema.

El ahorro forzoso es el abuso y la causa de las bajas pensiones. No financia una sola pensión en Chile ni lo hará jamás. Solo financia inversiones empresariales. Para eso fue diseñado y acumulado. El dinero allí registrado es considerado "sagrado" por los grandes empresarios que lo tienen en su poder...", escribió en una columna de opinión publicada en medio del debate que generó en Chile la demanda ciudadana de acceder a esos dineros. En concreto, parlamentarios de oposición presentaron un proyecto de ley para que los cotizantes pudieran retirar, por una sola vez, el $10 \%$ de su ahorro previsional, la idea puso en jaque uno de los pilares del modelo neoliberal implementado en Chile, la derecha, el empresariado y el gobierno cerraron filas en contra de la iniciativa.

Según las investigaciones realizadas por economistas de la Fundación Sol, un centro de estudios independiente, las AFP administraban a junio de 2020 un monto de 201 mil millones de dólares, dinero aportado por más de 9 millones de trabajadores chilenos afiliados al sistema. De este total, el $55 \%$ se invierte en Chile y el $45 \%$ restante en el extranjero. De lo que se destina al mercado local, un porcentaje va a financiar bonos de deuda del Estado, otro tanto se coloca en la banca privada como bonos y depósitos a plazo que capitalizan las ocho entidades financieras más importantes del país, las que pagan un interés anual del $3 \%$ a las Administradoras de Fondos Previsionales. El tema es que, si un trabajador pide un préstamo bancario en Chile, debe pagar un interés que fluctúa entre un $20 \%$ a un $30 \%$ anual. Por eso el negocio es redondo para la banca, le presta al trabajador el dinero de su propio ahorro previsional, pero a un interés 30 veces más alto que el que le paga a la AFP por disponer de esos recursos. En Chile nadie sabe para quien trabaja.

Las AFP también colocan parte de los ahorros previsionales de los trabajadores en empresas chilenas. La Fundación Sol calcula 
que más de 24 mil millones de dólares se destinan a acciones $y$ bonos para sociedades anónimas propiedad de los grandes grupos económicos locales. Empresarios que aparecen ligados a prácticas antisindicales, colusiones, evasión de impuestos, financiamiento ilegal de la política y daño medioambiental. Son 30 grupos económicos chilenos los que reciben dinero fresco para financiar sus proyectos. Esto explica en parte la reacción de la derecha $y$ el gobierno ante la demanda ciudadana por el $10 \%$ de los ahorros propiedad de los trabajadores. Lo otro es que, para hacer efectivo el retiro, se hacía necesario realizar una reforma a la Constitución, otro de los pilares sagrados e inamovibles del sistema.

El argumento del oficialismo fue que retirar dinero del ahorro previsional dañaría las pensiones futuras de los jubilados, pero no hizo mucho sentido entre la gente ya que todos saben que el $50 \%$ de quienes se han jubilado bajo este modelo, percibe una pensión de poco más de 151 mil pesos, equivalente a poco más de 200 dólares. Quienes ahorraron en este fondo privado durante 30 o 35 años no superan los 246 mil pesos de jubilación, o sea, cerca de 350 dólares. Nadie en Chile vive con esa suma. El monto del ahorro previsional además oscila según cómo las administradoras lo inviertan en la bolsa. Si las AFP le apuntan a las acciones correctas, la cifra sube y ellas ganan, pero si hay un descalabro bursátil, el monto del ahorro personal disminuye. Las AFP nunca pierden. Cuando hay ganancias ellas capitalizan, cuando hay perdidas, las descuentan del ahorro de sus afiliados y no de sus utilidades. Piñera amenazó con vetar el proyecto, la derecha extrema con solicitar que sea declarado inconstitucional si se aprobaba, pero en definitiva el clamor ciudadano pudo más y ante un eventual estallido social 2.0, el oficialismo se dividió en el Congreso y el ejecutivo no tuvo opción. A regañadientes Piñera promulgó la ley en una ceremonia privada.

El triunfo fue político, ya que demostró la factibilidad de cambiar las hasta ahora inamovibles reglas económicas del sistema y también la Constitución de Pinochet. El retiro del $10 \%$ de los fondos previsionales fue un respiro para la ciudadanía y un incentivo para la alicaída economía local. Ninguno de los catastrofistas augurios del gobierno, la derecha y el empresariado, se cumplió.

\section{EL EPILOGO}

A cinco meses del inicio de la pandemia, los casos diarios comenzaron a registrar una disminución en el país, lo que hizo al gobierno iniciar la reapertura y levantar algunas restricciones, pese a las críticas de los especialistas y gremios de la salud que advierten del inminente rebrote.

En Chile, al igual que en muchos países, la pandemia del coronavirus agudizó las precariedades sociales contra las que la ciudadanía se había manifestado en octubre de 2019, evidenció además la ineptitud del gobierno de Sebastián Piñera para enfrentar la crisis sociosanitaria y expuso nuevamente las debilidades del modelo económico-institucional que implementó la dictadura cívico militar a partir de 1973, pero también, demostró que es resorte de la ciudadanía cambiar las cosas y que las normas sagradas del modelo neoliberal impuesto en Chile no son inmutables.

El plebiscito que busca cambiar las cosas y que fue acordado a raíz del estallido social de 2019 está programado para octubre y pese a la pandemia $y$ al riesgo de enfermar durante el proceso, el $87 \%$ de los chilenos asegura que concurrirá a votar, según una encuesta realizada a fines de agosto por las consultoras Ipsos y Espacio Público. Eso es, porque el $65 \%$ de los encuestados considera que una nueva constitución traerá cambios positivos al país. El $80 \%$ dice que teme contagiarse de la enfermedad durante el escrutinio, pero el miedo no es suficiente para impedirles ir a votar. Y es que los chilenos le temen más al sistema económico y político que los rige, que al imparable coronavirus que amenaza con matarlos.

Chile estalló socialmente en octubre y la pandemia no ha hecho más que acrecentar 
la presión, pequeños triunfos ciudadanos han contenido nuevos estallidos, pero en octubre se cumple un año desde aquel viernes 18 , cuando la gente salió a las calles para exigir cambios profundos en el país. El plebiscito donde la ciudadanía resolverá si aprueba o rechaza una convención constituyente para redactar una nueva constitución, actuará como una válvula de escape y dará por primera vez a los chilenos, la posibilidad de ser partícipes de la edificación de su propio futuro.

\section{REFERENCIAS}

Durán, G. y Kremerman, M. (julio de 2017). Pobreza y fragilidad del Modelo. Nuevos indicadores para el debate sobre pobreza en Chile. Fundación Sol. https://fundacionsol.cl/blog/estudios-2/post/pobreza$y$-fragilidad-del-modelo-6107

Fecha de ingreso: $01 / 09 / 2020$ Fecha de aprobación: 23/10/2020 
